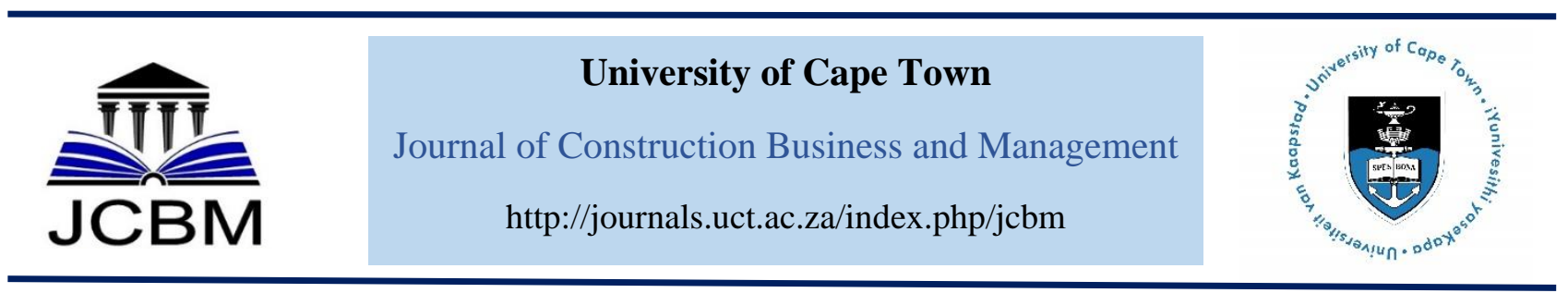

\title{
Correlation analysis between risk measurement and project success of small and medium contractors in Gauteng, South Africa
}

\author{
B. Y. Renault ${ }^{1}$, J. N. Agumba ${ }^{2}$ and N. Ansary ${ }^{3}$ \\ ${ }^{1}$ Department of Construction Management and Quantity Surveying, School of Civil Engineering and the Built \\ Environment, Univeristry of Johannesburg, South Africa. \\ ${ }^{2 \& 3}$ Department of Building Sciences, Faculty of Engineering and the Built Environment, Tshwane university of \\ technology, South Africa.
}

Received 18 April 2020; received in revised form 19 June 2020 and 10 August 2020; accepted 19 September 2020.

https://doi.org/10.15641/jcbm.4.2.884

\begin{abstract}
Risk measurement (RM) and construction project success (PS) are closely related. Preceding studies highlight the importance of RM in the management of risks without revealing its effect on PS. This study aims to determine the influence of RM on the PS of small and medium enterprises (SMEs). A positivist research design was applied using a survey questionnaire circulated to 181 respondents in Gauteng, South Africa (SA). Raw data analysed using inferential statistics extracted onecomponent solution and evinced statistical significance $(\mathrm{p}=0.000<0.05)$ between RM and PS. In particular, results revealed that RM significantly influences PS of construction SMEs through delimiting the RM criteria to be adopted, establishing the level of acceptable risk and risk timeframe relevant to risk effect and risk likelihood. It is suggested that the management of SMEs and industry professionals involved in risk management should adopt RM for the management of their project risks to accomplish project objectives effectively. The study renders new empirical evidence of risk management factors that influence PS of SMEs in the context of SA. It remains to be seen whether the current finding could be replicated in other datasets. If indeed that is the case, then this article expands to the discourse and literature on RM of SMEs. However, the current findings cannot be generalised due to the restrictions pertaining to the geographical area and respondents.
\end{abstract}

Keywords: Contractors, Correlation analysis, Factor analysis, Project success, Risk measurement.

\section{Introduction}

This study seeks to establish the influence of RM on construction PS of small and medium enterprises (SMEs). Considering the argument that risk matters and that it affects how managers and stakeholders make decisions, it follows logically that RM is a critical step towards managing risks. Canbolat and Gümrah (2015) observed the contrast between risk management and RM and defined risk management as the inclusive process that an organisation follows to outline a business strategy, to detect potential risks, to quantify them, and to understand and control their nature, while RM is a component of risk management that deals with the evaluation of risk exposures. A sample of SMEs was solicited to value the extent to which their company performs risk measurement practices at their project level. It was anticipated that the knowledge generated from this study would afford new insights and so inform risk management practice. This research employed a quantitative methodology to illustrate the topic under examination. It included a conveniently sampled group consisting of 181 respondents of established construction SMEs.

This study begins with a background that frames the study. Following this is the relevant literature which included: the need for risk management in the CI, an overview of construction SMEs in SA, risk management in SMEs, risk measurement, past risk management models, classification of risks, project success, and accompanying model constructs and hypothesised relationship. Also included in this study are the research methods, presentation of results, and discussion of

\footnotetext{
${ }^{1}$ Corresponding Author.

Email address: renault08@yahoo.fr
} 
findings. The study concludes with some contributions and limitations as well as areas for future work.

\subsection{Background}

Although the construction industry (CI) is indubitably known for its importance in economic development through employment provision and infrastructure development (Nawaz et al., 2019; Mwangi \& Ngugi, 2018), it has also been criticised for its poor performance (Osuizugbo, 2019; Muzondo \& McCutcheon, 2018). According to Potensis (2017), the construction sector accounts for $7 \%$ of global employment and contributes $10 \%$ to the global Gross Domestic Product (GDP). Some factors attributable to the poor performance of the industry are the undesirable health and safety (H\&S) record (Rehacek, 2017a; Sayilir \& Farhan, 2017), the recurrence of projects delivered over-budgeted cost, scheduled time and often not at the expected client's satisfaction levels (Albasara et al., 2018; Chileshe et al., 2016). However, these projects are predisposed to a high degree of risk; a reoccurring phenomenon in construction that, if it materialises, can deviate the project from its preestablished goals. The materialisation of time and cost risk can, in extreme cases, incapacitate the economic look of a project, thereby turning a potentially lucrative organisation into an unsuccessful company (Sifumba et al., 2017). The effects thereof may be quantified using many terms: increase cost, time overruns, destruction of property, injury to people, and at times a combination of all of these. It follows that management of risk, which might imperil the successful completion of a project is important to achieve PS. Risk management often commences with the identification of potential risks which is then followed by the RM phase, where the potential impact of risk is assessed, and risk responses are formulated. Al-Ajmi and Makinde (2018) clarified in their study that when conducted, RM helps quantify and place risks in some order of priority and highlights decisions to be made early, hence increases the likelihood of PS. They added that the effectiveness of subsequent stages of risk management usually depends on the evaluation of the likelihood and magnitude of risk.

\section{Need for risk management in the CI}

Nawaz et al. (2019) indicated that the CI is constructed around project-based organisations (PBOs) with short term and transient nature. This industry is inherently flexible and reconfigurable, adept at carrying out undefined and diverse tasks (ibid.). PBOs support businesses to attain success through managing complex services, responding to fast-changing markets, providing customer-focused innovation, coping with technical uncertainty, and offering cross-functional business expertise (Dandage et al., 2018). However, despite these potential advantages, the industry is faced with boundless uncertainties, as a result of the projects' multifaceted activities with clearly defined goals, resources, and time targets.

The CI comprises contracting and sub-contracting enterprises, engineering consultants, quantity surveyors, architects, suppliers and can cover a great variety of projects in engineering, building, offshore structures, and industrial plants which encompasses vast employment opportunities. Moreover, projects in the CI are inclined to more risks and uncertainties than other sectors (Maseko, 2017). To undertake a project from its conception to its completion, the activities and transformation within PBOs involve complex, frequently bespoke, and include timeconsuming design and costly production processes (Kotb $\&$ Ghattas, 2018). Projects are based on teamwork with varied skilled and interested stakeholders, and the cooperation among them is formed around extensive, dissimilar, and interconnected processes (Muchenga, 2016). Such complexity is further exacerbated by several external environmental factors (Chileshe et al., 2016).

Regardless of the heterogeneity and importance of the CI with its intrinsic risks, risk management has been sparsely applied and practised in recent years (Moshesh et al., 2018) and its reputation in contrast with other industries is relatively weak (Simota et al. (2017). Furthermore, although research into risk management abounds, there has been a scarcity of empirical studies that pursue to examine RM, the relationship between risk management factors and PS, specifically, the relationship between RM and PS of construction SMEs.

\subsection{Construction SMEs in South Africa}

The definition of SMEs based on the number of employees differs across nations. In the European Union (EU), SMEs are referred to as those enterprises with less than 250 employees for medium-sized enterprises. Certain nations put a boundary of 200 employees. In the United States of America (USA), a medium-sized enterprise is a firm with 500 or fewer employees. Smallsized enterprises, in contrast, are those firms with less than 50 employees while micro-enterprises employ up to 10 employees in the USA and EU. The magnitude of annual revenues is also used as a determinant in defining SMEs (Madani, 2018). In the EU, enterprises with annual revenue of not more than 50 million Euro are considered medium-sized enterprises, those with revenue equal to or fewer than 10 million Euro are considered small enterprises while enterprises with annual revenue fewer or equal to 10 million Euro are considered micro-enterprises.

The SA definition of SMEs in the CI based on the number of employees and annual turnover differ slightly from those of the EU and USA. The industry typically consists of dissimilar sizes of companies that is, micro, very small, small, medium, and large contractors (National Small business Act amended in 2004). These contractors can be differentiated from one another by their annual turnover, capacity, and extent of their fixed assets. Medium-sized contractors are referred to by the National Small Business Act (2004) as those contractors having between 50 and 200 full-time employees, with an average total annual turnover ranging from ZAR6m to ZAR26m and a total gross asset value (fixed property) ranging from ZAR1m to ZAR5m. As for small contractors, they are defined as enterprises employing less than 50 full-time employees, with average total annual amount turnover fewer than ZAR6m2 with a total gross asset value (fixed property) of fewer than ZAR1m. This study employed this definition given that previous studies (Muzondo \& McCutcheon, 2018; Naude \& Chiweshe, 2017) in SA have employed it. 
The SME construction sector is central to the SA economy. It is reported that $78.5 \%$ of firms in the SACI are SMEs and the industry employed 1395000 people, accounting for 9, 6\% on average of GDP between 2008 and 2016 (StatsSA, 2018). However, these enterprises are viewed as high-risk enterprises since their entry, and exit levels in the market are high. It is believed that $70 \%$ of construction SMEs fail in their first year of existence (Construction Industry Development Board (CIDB), 2017).

The reasons for the high failure rate of construction SMEs are numerous and diverse. Some studies (Rambo \& Oketch, 2018; Leboea, 2017) mention compliance with legislation, resource scarcity, rapidly changing technology, lack of management skills, and lack of management commitment. Others (Rungani \& Potgieter, 2018; Muzondo \& McCutcheon, 2018) highlight factors such as managerial incompetence, lack of managerial experience, inadequate planning, and poor financial control. However, a recent study (Mafundu \& Mafini, 2019) found that in SA, SMEs lack the skills to implement risk management and are generally inadequately equipped to deliver projects successfully.

\subsection{Risk management in SMEs}

According to Hwang et al. (2014), not only SMEs encounter more uncertainties and challenges than large enterprises but also, they lack resources to respond promptly to hazards that have the potential to engender massive losses and even bankruptcy of the firm. As a result, SMEs need to practise risk management much more than large enterprises (Zoghi, 2017) and consider risk management as an integral part of the business management to keep the firms viable and productive (Naji $\&$ Ali, 2017). However, in order to attain a competitive edge and increase the rate of success of their business, SMEs need to make risky decisions and participate in risky activities so that they can protect the innovativeness of delivering projects (Hove \& Banjo, 2018).

Albasara et al. (2018) explained that construction professionals' inadequate level of knowledge in risk identification, risk analysis, risk response strategies, and communication affected the implementation of risk management. In line with this statement, Rehacek (2017a) indicated that even management with regular use of risk management finds it difficult to understand the rationale for and formal process of risk management in new projects. Diversity in parties' perceptions in a construction project invites undesirable biases in decision making, which makes the process of managing risk more complex (Naji \& Ali, 2017). Many researchers (Moshesh et al., 2018; Al-Ajmi \& Makinde, 2018; Sayilir \& Farhan, 2017) believe that few organisations practise formal risk management systems with analytical approaches in assessing risks. In their study, the 'human problem' was identified as the initial hindrance for risk management implementation.

Furthermore, in examining the impact of projects' characteristics on risk management implementation in construction enterprises, Chileshe et al. (2016) stressed that the time commitment is related to many aspects of risk identification and analysis. In the same way,
Fernando et al. (2018) concluded that organisations in the $\mathrm{CI}$ irregularly practise formal risk management owing to the projects' just-in-time characteristics. Similarly, van Winsen et al. (2016) found out that the 'organisation problem' was the main factor that prevents construction organisations from implementing risk management. Lack of time and lack of dedicated resources were also identified as significant hindrances to risk management adoption. Baloyi and Ozumba (2020) also asserted that the development of a risk management framework is a time-consuming process that is, at times, inconsistent with projects' allocated budgets.

Recent research within the context of developing economies indicated that lack of experience, inadequate information, and awareness of risk management processes are the most significant challenges which affect the implementation and practice of risk management in the CI (Jaskowski \& Biruk, 2019; Rwelamila, 2018; Firmenich, 2017). However, in contrast, 'time and resources constraints' were ranked least important. Omer and Adeleke (2019) found that the low level of familiarity with techniques and the inability to recognise the benefits of the process were the most influential factors which impact the adoption of risk management. Teuma (2019) stated that due to the manpower size of SMEs in the industry, they mostly suffer from inadequacy of facilities to provide risk management training. This is also compounded by the absence of a holistic approach for risk management in standards and professional bodies which makes both understanding and implementation of risk management more complicated (Oduoza et al., 2017). Conversely, Szymansk (2018) argued that all enterprises, including SMEs, need to adopt risk management in order to identify, evaluate risk, and respond to potential threats. Fernando et al. (2018) believe that risk management would be an impossible task if risks cannot be measured; that without measuring risk, it will be almost impossible for an organisation to ascertain what actions to take to enhance opportunities and limit threats and the related consequences of risks, should they eventuate.

\subsection{Risk measurement (RM)}

The overall aim of RM is to identify and measure the significant exposures in terms of possible loss to the organisation (Williams, 2016). Some authors defined RM as the process of quantifying and placing risks in some order of priority and highlights decisions to be made (Simota et al., 2017), the evaluation of the likelihood and extent (magnitude) of risk (Acharya et al., 2017). Others (Deloach, 2018; Naude \& Chiweshe, 2017) explained the distinction between RM and a risk measure and defined $\mathrm{RM}$ as the process of applying measures to enumerate the risk, while a risk measure was defined as the operation that assigns a value to risk. Any enterprise needs to be able to quantify risk before deciding whether the specific risk is perilous enough to commit resources to manage (AlAjmi \& Makinde, 2018). If such resources have been committed, then the organisation needs RM to see whether the risk management process has minimised risk.

It has been generally acknowledged that RM is conducted by using probability and statistical analysis of historical data (Segal, 2019). The probability that risk will 
occur is a measure of its likelihood of occurrence. As a result, "standard deviation" is the most common unit now used for RM. However, Canbolat and Gümrah (2015) argued that evaluating risk measurement by computing the relative frequency of known events is often inappropriate, untrustworthy, and misleading as underreporting could occur. Moreover, Omer and Adeleke (2019) observed that using historical data usually does not reflect the probable severity of an occurrence, simply the consequence; they reflect results, not causes.

\subsection{Past risk management models}

Many risk management and measurement models have been developed in recent years. For example, Firmenich (2017) investigated the relationship between risk management and PS. the model comprises risk management components which include: risk planning, risk identification, risk measurement, risk response planning, and risk monitoring and review. Risk measurement was defined by a classification system of high, medium, and low risk. It was found that risk measurement did not influence the subjective performance of the project. However, respondent rated risk measurement as one of the key components of risk management. It was observed that the decision as to which measures should be employed to respond to risks depend on the risk measurement criteria used.

Simota et al. (2017) study concluded that risk measurement, when applied assists in placing risks in some order of priority and highlights decisions to be made. Risk measurement was termed as the risk measurement criteria to be employed in evaluating risk and was defined in terms of risk materiality, risk terminology, and risk timeframe. Risk terminology which classifies the impact and probability or risk occurring was found to be the measurable indicator of risk measurement in projects of SMEs. Similar conclusions were drawn in Naude and Chiweshe's (2017) research on SMEs in SA. However, in their study, risk measurement was also defined by risk timeframe in addition to risk terminology. It was found that when used, risk timeframe warns when the risk will impact the project, should it occur.

Furthermore, the level of acceptable risk was found to be a core measuring statement of risk measurement in a study conducted by Szymansk (2017). Knowing that realistically risk often cannot be curtailed to zero, acceptable risks may help set realistic targets for risk management. However, Al-Ajmi and Makinde (2018) found that management may be uncertain about defining their acceptable level of risk owing to a lack of knowledge of the process underlining threats which can negatively affect project objectives.

The measures mentioned above are common in risk management after risk has been identified. Although the use of different measures in the literature indicates the lack of consent of what should constitute risk measurement, and knowing that new models and concepts that govern risk measurement will develop continuously as a result of the changing construction business milieu, the measures used in the current literature were embraced as the measuring statements of risk measurement in the study. Therefore, the foregoing intended to facilitate the measuring of risk measurement:
- Risk measurement to be employed. This indicates a classification system to be used (high, medium or low), or numbers ranging from 1 to 10 with $1=$ extremely rare or negligible risks and $10=$ almost certain or catastrophic risks.

- Risk materiality, i.e. indicating when risk is significant.

- Risk timeframe. Relevant to risk effect and risk likelihood. i.e. when is risk supposed to eventuate

- Risk terminology. i.e. the use of terms such as impact/consequence/effect and likelihood/probability/frequency.

- Level of acceptable risk. i.e. the risk tolerance level of the project utilised to direct the flow of project resources.

In order to facilitate data analysis, each measure was assigned a label, as presented in Table 1.

Table 1: Respondents' Profile

\begin{tabular}{cll}
\hline Factor & \multicolumn{1}{c}{ Measures } & Label \\
\hline & $\begin{array}{l}\text { Define the risk measurement to be } \\
\text { used }\end{array}$ & RM1 \\
Risk & $\begin{array}{l}\text { Defines the risk materiality } \\
\text { measurementefines }\end{array}$ & RM2 \\
(RM) & $\begin{array}{l}\text { Defines the risk timeframe } \\
\text { Determine the level of acceptable }\end{array}$ & RM3 \\
& $\begin{array}{l}\text { RM5 } \\
\text { risk }\end{array}$ \\
\hline
\end{tabular}

\subsection{Classification of risks}

Risk classification seeks to structure the numerous risks affecting construction projects. Various classifications have been suggested in the literature. Al-Ajmi and Makinde (2018) outlined a list of risk factors emanated from various sources: financial risks, construction risks, and design risks. In another view, the source of risks was used as a basis for their categorisation as physical risks, personal risk, technical risk, safety risks, design risks, political and regulatory risks, financial risks, and contractual risks (Nawaz et al., 2019). According to Szymansk (2017), risks in construction are in the categories of risks bearable by contractors, consultants, and clients. Although risks can be classified differently, Nawaz et al. (2019) argued that the motivation for choosing a classification must serve the aim of the research. Since the main study aimed to establish the influence of RM practices on PS, it was therefore important to identify the risks that can significantly influence project success. In the current study, the success of a building project could be regarded as the completion of a building within budgeted cost, scheduled time, at the required quality, and without $\mathrm{H} \& \mathrm{~S}$ issues. Naji and Ali (2017) hold the view that there is more to successful project outcome than just focusing on the triple dimensions time, cost, and quality. Consequently, risks were classified in the study based on their impact on cost, time, quality, and $H \& S$ requirements, substantiating Rehacek (2017a). They were, therefore termed as timerelated risk, cost-related risks, quality-related risks, and $\mathrm{H} \& \mathrm{~S}$ related risks.

\subsection{Project success (PS)}

Previous studies have investigated the outcome measures of PS in construction. Most of them have suggested 
various outcome measures. For instance, Osuizugbo (2019) and Albasara et al. (2018) suggested scheduled time, budgeted cost, and desired quality as the leading success outcome measures. These were referred to as the Iron Triangle. However, Szymansk (2017) stated that although other measures of PS have emanated, the iron triangle is nearly quoted in every PS related study; PS measures should not be circumscribed to the iron triangle. As a result, the latter believe that PS measures should include achievement of design goals, impact on the enduser, organisational success, benefits to the country's national infrastructure in addition to the iron triangle. Okereke (2017) identified seven (7) measures of PS, which comprised the iron triangle and the other four (4) metrics. The four metrics are resolving key operational issues, technical performance, end-user, and project team's satisfaction, and H\&S. According to Naude and Chiweshe (2017), the project is an utter success if it reaches the operational and technical requirements to be performed, and if there is contentment between the ultimate end-user and project team members concerning the project result. Williams (2016), on the other hand, recommended including the absence of legal claims as a dimension of a successful outcome in SME projects. This implies the significance of incorporating safety as a success dimension given that it is rational to foresee that if unfortunate incidents occur, contract delay, financial loss, and legal claims may be incurred by both contractors and clients. The use of diverse parameters of PS outcome is an indication that there is no consensus in the literature pertaining to the measures of defining project success in SMEs projects. Despite the vagueness in defining PS outcome, this paper identified five (5) measures as tabulated in Table 2.

Table 2. Project success measures

\begin{tabular}{|c|c|c|}
\hline $\begin{array}{c}\text { Project success } \\
\text { outcome }\end{array}$ & Label & Source \\
\hline $\begin{array}{l}\text { Meet time objectives } \\
\text { for key milestones }\end{array}$ & PS1 & $\begin{array}{l}\text { Osuizugbo (2019) } \\
\text { Albasara et al. (2018) } \\
\text { Osuizugbo (2019) } \\
\text { Osuizugbo (2019) }\end{array}$ \\
\hline $\begin{array}{l}\text { Meet cost objectives } \\
\text { for the project }\end{array}$ & PS2 & $\begin{array}{l}\text { Albasara et al. (2018) } \\
\text { Osuizugbo (2019) } \\
\text { Albasara et al. (2018) }\end{array}$ \\
\hline $\begin{array}{l}\text { Meet quality } \\
\text { objectives for the } \\
\text { project }\end{array}$ & PS3 & $\begin{array}{l}\text { Osuizugbo (2019) } \\
\text { Albasara et al. (2018) } \\
\text { Osuizugbo (2019) } \\
\text { Albasara et al. (2018) }\end{array}$ \\
\hline $\begin{array}{l}\text { Meet the required } \\
\text { health and safety levels }\end{array}$ & PS4 & Williams (2016) \\
\hline $\begin{array}{l}\text { Meet expected client's } \\
\text { satisfaction levels }\end{array}$ & PS5 & $\begin{array}{l}\text { Okereke (2017) } \\
\text { Naude and Chiweshe (2017) }\end{array}$ \\
\hline
\end{tabular}

\subsection{Model constructs and hypothesised relationship}

Figure 1 depicts the conceptual framework used in the study. The rectangles denote the measurable variables, while the ovals denote the observed variables. The framework depicts the influence of RM on PS as well as their hypothesised relationship. RM and PS were named explanatory and response variables, respectively. Five measures determined each variable; measures of RM included: 1) define the risk measurement to be used;2)
The explanatory variable Response variable

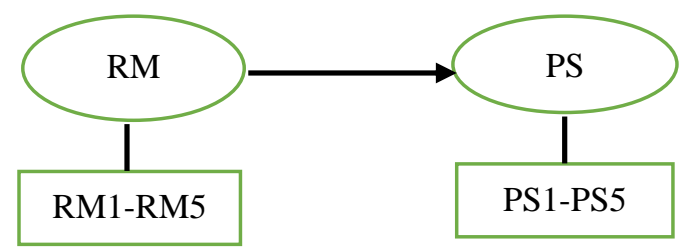

define the risk materiality; 3 ) define the risk timeframe applicable to risk impact and risk probability; 4) clarify the risk terminology; and 5) determine the level of acceptable risk. Those of PS are 1) time objective; 2) cost objective; 3) quality objective; 4) Health and safety levels; and 5) client satisfaction levels. The relationship between the variables is discussed below.

\section{Figure 1. Conceptual framework}

According to Firmenich (2017), defining and documenting RM is central to project success. The author pointed out that RM helps elucidate the risk measurement criteria to be adopted, determine risk materiality, define the level of acceptable risk and risk timeframe relevant to risk effect, and risk likelihood. Simota et al. (2017) study concluded that in order to attain project outcomes effectively, a project team has to outline a classification rule set for each applicable impact type. Similarly, it was observed that RM, when applied, can determine the significant influences on PS and consequently help determine the effects of uncertainty. Supporting the latter statement, Williams (2016) indicated that RM criteria is an advanced activity of risk management system and established that when it is applied, it lessens risk impact in terms of schedule, budget as well as quality. From the above discussion, it can be said that there is a relationship between RM and PS; therefore, the following hypothesis was proposed for testing:

$\mathrm{H}_{0}$ : Risk measurement does not have a positive influence on project success.

$\mathrm{H}_{1}$ : Risk measurement has a positive influence on project success.

\section{Research methods}

The study adopted a quantitative method based on a positivist paradigm, employing a structured questionnaire. An in-depth review of related literature was primarily undertaken to specify the variables and their measurable statements. The questionnaire was piloted, reviewed, and amended by experts and a professional statistician for ease of data analysis before being selfdistributed to construction SMEs in Gauteng. The rationale for choosing Gauteng as the study area is that not only it is the economic hub of SA contributed to $34 \%$ of the GDP of the entire country (The Real Economy Bulletin, 2016) but also due to the large concentration of contractors in the province. The data gathered were analysed using SPSS software package version 23, computing both descriptive (frequency and central tendency) and inferential statistics (exploratory factor analysis (EFA) and multiple regression analysis (MRA)). A detailed methodology is presented hereunder. 


\subsection{Sample and sampling design}

The sample size was obtained using the general Rule of Thumb based on an estimated population of 661 retrieved from the CIDB website. The survey targeted contractors graded from 1 to 6 (denotes small and medium enterprises) of the CIDB grading system. There are nine grades of contractors in the SACI, ranging from 1 to 9 . The criteria for selecting the study population was that respondents must be operating at the management level of the enterprise and be working for established construction SMEs with valid registration with the CIDB register of contractors. Convenience sampling was used to identify and select respondents who included owners, quantity surveyors, project and construction managers.

\subsection{Research instrument}

The research instrument comprised five parts with a covering letter that delineated the research aim. Sections 1 to 4 reported respectively on basic information about the respondent and the company, project risks, obstacles to risk management implementation, and risk management practices. Section 5 profiled questions related to risk management factors and performance outcomes of projects. Forty-two (42) variables that defined nine (9) risk management constructs were identified from an extant literature review. The current paper reported the results of one (1) construct only: risk measurement. Respondents were solicited to value the extent to which their company performs the identified risk measurement variables, using a closed-ended 5-point Likert scale-type questions. The responses were: $1=$ To no extent, $2=\mathrm{A}$ low extent, 3= A moderate extent, 4=A large extent, 5=A very large extent.

In total, 225 survey questionnaires were circulated to construction SMEs using drop and collection methods. A total of 187 were returned, yielding a response rate of $83 \%$. Conversely, six questionnaires were discarded owing to several ambiguities (missing data or information inappropriately filled in). Therefore, the remaining 181 were all utilised for the empirical analysis and conformed to the recommended sample size for regression analysis. This equates to a response rate of $80 \%$ which is considered high and could have been because of the method employed to gather data in the current study which has also yielded a high response rate in previous studies (Naude \& Chiweshe, 2017; Sifumba et al., 2017) conducted on construction SMEs in SA.

\subsection{Validity and reliability}

Construct validity and reliability of the RM and PS measures were also assessed. In order to achieve construction validity, content validity, convergent validity, and discriminant validity were scrutinised. Content validity was achieved through an in-depth literature review, expert reviews, and pilot-testing the survey with 15 top management personnel who were knowledgeable of the risk management practices they have been using for the management of their project risks. Convergent validity was verified by inspecting whether the scores of items load together on a sole component. According to Hair et al. (2018), factor loadings of values ranging between 0.40 and 0.45 are considered significant for a sample size of 150 and 200, respectively. The sample size of the current study is 181 , and a threshold of 0.40 was embraced. All the items loaded strongly on the single component with values above 0.40 (Table 6); hence convergent validity was supported. Next, discriminant validity was tested by examining the variable correlation matrix (Table 4). The correlation between the variables should not exceed 0.70 (ibid.). The item intercorrelations for all the variables in the construct attained correlations below 0.70 , signifying that discriminant validity was demonstrated.

Contrarily, reliability was achieved by computing the internal consistency of the variables employing Cronbach's alpha coefficient. A lower boundary of 0.70 is often recommended (Pallant, 2016.). However, a lenient threshold of 0.60 is prevalent in exploratory research, and coefficients near 1 imply good internal consistency reliability for the scale (ibid.). The study adopted a threshold of 0.60 . The Cronbach alpha coefficients ranged from 0.907 to 0.933 for measures of risk measurement with an overall coefficient of 0.935 . For measures of project success, the coefficients ranged from 0.659 to 0.852 with an overall coefficient of 0.786 . These values were all above the threshold of 0.60 , suggesting that the instrument is reliable. This is consisting of Hair et al. (2018) recommendation.

\subsection{Analysis of data}

Both descriptive and inferential (Factor analysis (FA) and MRA, respectively) statistics were used in the study. Descriptive statistics were applied to examine demographic information. There are two main approaches to FA: Exploratory Factor Analysis (EFA) and Confirmatory Factor Analysis (CFA). This study employed EFA to test the factorability of the data set. Hair et al. (2018) contend that EFA is useful for creating new theories or creating a new construct that does not exist and do not set any a priori constraints on the number of components to be extracted. Whereas FA takes a confirmatory approach when the researcher has preconceived thoughts on the actual structure of the data, based on theoretical support or prior research; that is to assess the degree to which the data meet the expected structure. In other words, CFA is used for testing (confirming) instruments that have been tested in previous studies (instruments or scales that have extensively been tested for their validity and reliability). The study is exploratory, and the concept explored is new.

Furthermore, the methods used in the study do not directly provide the necessary structure for formalised hypothesis testing. Therefore, EFA is an appropriate factor analytic technique for this study. Preliminary considerations were checked before conducting EFA: the suitability of the data set, factor extraction, rotation, and interpretation. The suitability of the data was achieved by satisfying the sample size prerequisite of $150+$ (Pallant, 2016). The current sample size of 181 is greater than the recommended size. Bartlett's test of sphericity $(\mathrm{p} \leq 0.05$, signifies statistical significance) and the Kaiser-MeyerOlkin (KMO) measure of sampling adequacy were also generated to help assess the suitability of the data. Factor extraction was assessed using Kaiser's criterion and the scree test. Factor rotation and interpretation of underlying 
structures of the theorised variables were achieved using Oblimin with Kaiser Normalisation. Missing data were eliminated using listwise deletion. Outliers were identified by checking the scatterplot, which revealed data points that are outliers and away from the main cluster of points. These were removed from the data set.

MRA was conducted to explore the correlation between RM and PS, by establishing the influence of RM on PS of SMEs. Prelusive analyses were carried out not to violate assumptions of generalisability (sample size), multicollinearity and singularity, normality, outliers, and linearity and homogeneity of variance (homoscedasticity). The current sample size is 181; hence, the sample size of $\mathrm{N}>50+8 \mathrm{~m}$, where $\mathrm{N}$ denotes the number of independent variables under study was met (Tabachnick \& Fidell, 2019). Multicollinearity among variables was used to eliminate collinearity; two methods were used; the Tolerance and Variance Inflation Factor (VIF). Cut-off points of values less than 0.10 for Tolerance and above 10 for VIF signify the presence of multicollinearity (Pallant, 2016). Therefore, this study used the proposed cut-off points to identify the multicollinearity among the variables. Running correlations ensured singularity among independent variables (from the main study). The results revealed bivariate correlations of coefficients which ranged from 0.304 to 0.630 . These coefficients were all less than the recommended value of 0.90 (Tabachnick \& Fidell, 2019). Multivariate analysis was used to assess normality and the presence of outliers in the data. Normality of data was assessed through statistical (skewness and kurtosis), graphical approaches (histograms and box plots), and the Kolmogorov-Smirnov test. Statistical approaches established that the data was slightly non-normal. The non-normality of the data was rectified by maximum likelihood estimation. An inspection of the box plot of each variable was used to identify outliers. Few outliers were identified; hence no items were removed in the study. A scatterplot was used to assess the homoscedasticity and independence of residuals. MRA was subsequently applied to establish the extent to which project success of SMEs is influenced by risk measurement. The standardised beta weight of the explanatory variable was inspected to scrutinise the statistical significance and relative contribution of the variable. The beta coefficients indicate how strongly the explanatory variable influences the response variable. Consequently, the higher the beta value, the greater the influence of the explanatory variable on the response variable. Due to the nature of the study, which requires statistical significance, $p<0.05$ was adopted as the statistical level of significance, in line with Field (2013). The null hypothesis was rejected for a p-value smaller than 0.05 .

\section{Results}

\subsection{Demographic profile of the respondents}

Among the respondents, $30.90 \%$ were owners, $22.10 \%$ were owner-managers, $17.10 \%$ were project managers, and $15.50 \%$ were managers. Other positions such as quantity surveyors and civil engineers were represented by $14.40 \%$, indicating the various types of professions represented in the industry. $22.90 \%$ of the respondents had matriculation, $2.80 \%$ had no qualification, and $14.50 \%$ had attended basic schooling. The remaining $59.80 \%$ had graduated with a post-secondary school qualification $(1.70 \%$ had a Doctorate, $6.10 \%$ had a Master's degree, $15.10 \%$ had an Honours/BTech/BSc degree, $16.20 \%$ had a Higher National Diploma/Diploma and $20.70 \%$ had another certificate). The percentage of respondents with post-secondary school qualification implies that the respondents are qualified to respond to the questions.

In terms of years of experience in construction and type of contractor, it was found that $18.10 \%$ of respondents had construction experience ranging from 1 to 5 years, $28.90 \%$ had experience ranging from 6 to 10 years, $30.80 \%$ had between 11-20 years of experience, $16.80 \%$ had between 21-35 years of experience, while only $5.40 \%$ had over 36 years of experience in construction. The year bracket $11-20 \quad(30.80 \%)$ predominate construction experience, followed by $6-10$ $(28.90 \%)$ and $21-35(16.80 \%)$. This demonstrates that the respondents have spent a considerable number of years in the $\mathrm{CI}$ and are, therefore, familiar with $\mathrm{RM}$ practices. $38.20 \%$ of these contractors were Sub-contractors, $32 \%$ were General contractors, and $29.80 \%$ were either Civil contractors $(6.70 \%)$, Specialist contractors $(18 \%)$, or Home building contractors $(5.10 \%)$. These results indicate the involvement of SMEs in various types of business.

\subsection{Success Factors for Social licence Acquisition \\ 4.2.1 Risk measurement (RM)}

Raw data were analysed using SPSS version 23, computing EFA. Before computing EFA, the appropriateness of the data set for factor analysis was computed. The KMO, which is an adequate indicator to check the sample adequacy, recorded a value of 0.837 (Table 3), above the suggested threshold of 0.60 . Further, Bartlett's Test rendered a p-value of 0.000 $(<0.05)$, implying statistical significance and therefore, a possibility of conducting factor analysis (Pallant, 2016).

Table 3: KMO and Bartlett's test

\begin{tabular}{llc}
\hline \multicolumn{2}{c}{ Kaiser-Meyer-Olkin Measure of Sampling } & $\mathbf{0 . 8 3 7}$ \\
& Adequacy & \\
\hline \multirow{2}{*}{ Bartlett's Test of } & Approx. Chi-Square & 881.528 \\
Sphericity & df & 10 \\
& Sig. & 0.000 \\
\hline
\end{tabular}

Next, correlation Matrix (Table 4) which shows how an item is related with other items of the scale disclosed several coefficients above 0.30 , ranging from 0.603 to 0.870 , indicating that the five measures (RM1, RM2, RM3, RM4, and RM5) were good measures of the factor risk measurement.

Likewise, communalities (Table 5) yielded coefficients greater than the threshold of 0.50 (Hair et al., 2018), signifying that each item satisfactorily relates to other items. Therefore, these items similarly share the common core of the construct that is supposed to measure. 
Table 4. Correlation matrix

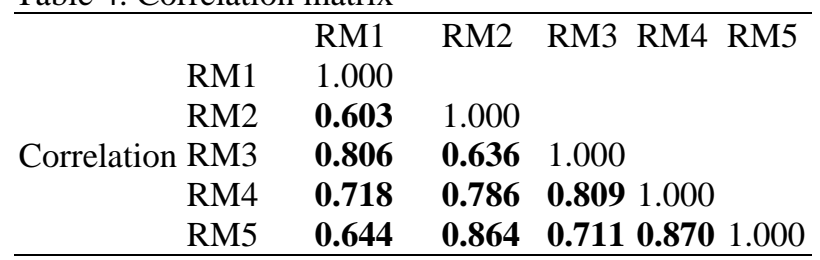

Note: Coefficients above 0.30 are bolded

Table 5. Communalities

\begin{tabular}{lcc}
\hline & Initial & Extraction \\
\hline RM1 & 1.000 & 0.707 \\
RM2 & 1.000 & 0.762 \\
RM3 & 1.000 & 0.787 \\
RM4 & 1.000 & 0.885 \\
RM5 & 1.000 & 0.846 \\
\hline Extraction method: Principal Component Analysis
\end{tabular}

The choice on the number of components to extract was based on eigenvalues, total variance explained (Table 6), and Scree-plot (Figure 2). Of the five measures supposed to measure risk measurement, only one component/item (shown in bold) had an eigenvalue (3.985) above 1. Using the Kaiser criterion (retained all components with eigenvalues above 1), only this component could be retained. It explained $79.70 \%$ of the variance and accounting for $79.70 \%$ of the overall variance. According to Yong and Pearce (2013), 60\% of the total variance could be adopted as the lowest acceptable level if the extracted component explained $60 \%$ of the total variance. Consequently, extracted one-component-solution is suitable since the sole component explains $79.70 \%$ of the total variance of the construct of construction risk measurement. It is supposed that this one-componentsolution is simple, parsimonious, and concurs with literature.

Table 6. Percentage variance explained-risk measurement

\begin{tabular}{lccc}
$\begin{array}{c}\text { Component Eigenvalue } \\
\text { Item }\end{array}$ & $\begin{array}{c}\text { \% of explained } \\
\text { Variance }\end{array}$ & $\begin{array}{c}\text { Cumulative } \\
\text { \% }\end{array}$ \\
\hline RM1 & $\mathbf{3 . 9 8 5}$ & $\mathbf{7 9 . 7 0 0}$ & $\mathbf{7 9 . 7 0 0}$ \\
RM2 & 0.548 & 10.964 & 90.664 \\
RM3 & 0.224 & 4.487 & 95.151 \\
RM4 & 0.143 & 2.862 & 98.013 \\
RM5 & 0.099 & 1.987 & 100.000 \\
\hline
\end{tabular}

Table 7. Component matrix

\begin{tabular}{lc}
\hline & Component \\
& 1 \\
\hline RM4 & 0.941 \\
RM5 & 0.920 \\
RM3 & 0.887 \\
RM2 & 0.873 \\
RM1 & 0.841 \\
\hline
\end{tabular}

Besides, an examination of the scree-plot which evinced a clear break after the second component supported the decision to retain only one component for supplementary examination (Figure 2) using Catell's
(1966) scree test. This decision was also reinforced by the results of principal axis factoring (Table 7), which unveiled strong loadings (above o.40) of the five items. As evinced by Hair et al. (2018), only items that load on a sole factor are retained. This result suggests that a onefactor solution is likely to be more appropriate (Pallant, 2016).

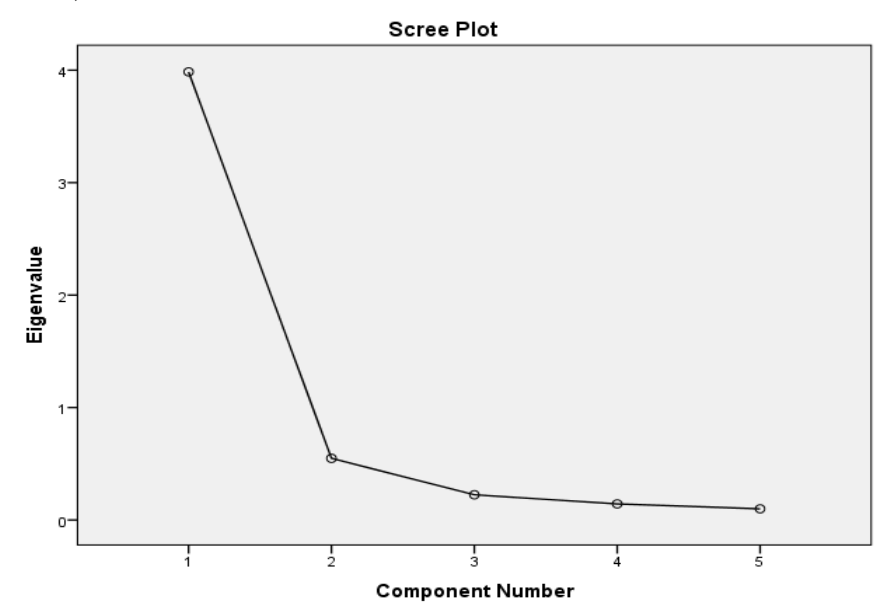

Figure 2. Scree plot

\subsubsection{Project success (PS)}

Table 8 presents the EFA results of PS measures. Three of the five measures of project success had eigenvalues exceeding 1 (1.954; 1.217; and 1.003), explaining $39.08 \%$; $24.35 \%$; and $20.06 \%$ of the variance and accounting for $83.49 \%$ of the overall variance to a successful outcome. The results indicate that PS of SMEs is defined by three variables namely; "meeting time objectives for key milestones", meeting cost objectives for the project", and "meeting quality objectives for the project". Oblimin with Kaiser Normalisation was subsequently applied to supplement the decision to retain three variables, which disclosed strong loadings of the variables. Hence, enough evidence of convergent validity was rendered for this construct.

Table 8. EFA results of the successful outcome of SMEs construct projects

\begin{tabular}{ccccc}
\hline Component Variable Eigenvalue & $\begin{array}{c}\text { \% } \\
\text { Explained } \\
\text { Variance }\end{array}$ & $\begin{array}{c}\text { Factor } \\
\text { loading }\end{array}$ \\
\hline & PO1 & $\mathbf{1 . 9 5 4}$ & $\mathbf{3 9 . 0 7 9}$ & 0.790 \\
Project & PO2 & $\mathbf{1 . 2 1 7}$ & $\mathbf{2 4 . 3 5 0}$ & 0.890 \\
success (PS) & PO3 & $\mathbf{1 . 0 0 3}$ & $\mathbf{2 0 . 0 6 4}$ & 0.913 \\
& PO4 & 0.501 & 10.020 & 0.936 \\
& PO5 & 0.324 & 6.487 & 0.612 \\
\hline Extraction method: Exploratory Factor Analysis \\
Rotation method: Oblimin with Kaiser Normalisation
\end{tabular}

4.3 Results of Multiple Regression Analysis (MRA) 4.3.1 Influence of RM on PS of construction SMEs MRA was used to model the correlation between RM and PS of construction SMEs by statically establishing if the explanatory variable (RM) had a significant influence on the response variable (PS). Before testing the hypothesised correlation between the variables, precursory tests were undertaken to ensure observance of the assumptions underlying regression analysis. The 
hypothesis tested was as per the conceptual framework in Figure 1.

Of the five measures (RM1, RM2, RM3, RM4, and RM5), only one measure (RM3) reached statistical significance (i.e., $\mathrm{p}=0.052<0.05$ ) with a significant unique contribution of $28 \%$ (beta $=0.281$ ) as shown in Table 9. It was further revealed that RM explained $13 \%(\mathrm{R} 2=0.130)$ of the variance in PS of construction SMEs (Table 10). This was an indication that RM is not a good predictor of PS owing to the low R2 obtained. However, analysis of variance (ANOVA) in Table 11 suggested that the model attained statistical significance $(\mathrm{p}<0.05)$. This signifies that PS is influenced by one measure (RM3) and the influence of RM is significantly different from the value of 5.227 (F value). Therefore, the null hypothesis (H10) that RM does not influence PS could not be supported. This implies that, the alternative hypothesis (H1), that RM influences PS of construction SMEs may be accepted.

Table 9. Coefficients- Influence of RM on PS

\begin{tabular}{lccccc}
\hline \multirow{2}{*}{ Model } & \multicolumn{2}{c}{ Unstandardised } & $\begin{array}{c}\text { Standardised } \\
\text { Beta }\end{array}$ & Sig. & Zero-order correlations \\
\hline (Constant) & 19.098 & 0.310 & & 0.000 & 0.310 \\
RM1 & 0.166 & 0.150 & 0.135 & 0.269 & 0.152 \\
RM2 & -0.218 & 0.164 & -0.188 & 0.186 & 0.339 \\
RM3 & 0.362 & 0.185 & $\mathbf{0 . 2 8 1}$ & $\mathbf{0 . 0 5 2}$ & 0.261 \\
RM4 & 0.024 & 0.214 & 0.019 & 0.912 & 0.216 \\
MR5 & 0.081 & 0.193 & 0.075 & 0.674 & \\
\hline
\end{tabular}

Table 10. Model summary- Influence of RM on PS

\begin{tabular}{lcccc}
\hline Model & $\mathbf{R}$ & $\mathbf{R}^{\mathbf{2}}$ & Adjusted $\mathbf{R}^{\mathbf{2}}$ & Std. Error of the Estimate \\
\hline & 0.360 & 0.130 & 0.105 & 1.39564 \\
\hline
\end{tabular}

Table 11: ANOVA- Influence of RM on PS

\begin{tabular}{lccccc}
\hline & Sum of Squares & df & Mean square & F & Sig. \\
\cline { 2 - 6 } Regression & 50.901 & 5 & 10.180 & 5.227 & 0.000 \\
Residual & 340.866 & 175 & 1.948 & & \\
Total & 391.768 & 180 & & & \\
\hline
\end{tabular}

\section{Discussion}

\subsection{Correlation between RM and PS}

The correlation between the explanatory variable RM and the response variable PS was significant $(\mathrm{p}=0.000<0.05)$. This was a clear indication that RM influenced PS through elucidating the risk measurement criteria to be adopted, establishing the level of acceptable risk and risk timeframe relevant to risk effect and risk likelihood. This result is not surprising as it substantiates Fernando et al. (2018) who observed that cost-effective risk management is naturally dependent on RM. If RM is deemed insignificant or is poorly conducted, then the chances of successfully handling risk go way down. The current result also substantiates the recent studies carried out by Lu et al. (2019) and Rambo and Oketch (2018) for Chinese and Kenyan construction SMEs respectively where it was concluded that RM of management processes is a robust attribute of construction SMEs corporate establishments for constant enhancement and innovation, and higher-level performance. Simota et al. (2017) also explain the importance of RM in helping stakeholders make well-informed decisions, evading conflicts, and increasing success. Williams (2016), believe that the practice of RM is indicative of the quality and consistency of security risk management processes. Without measuring risk, we cannot ascertain what response measures the enterprise should take to optimise the project risk-reward trade-off. Acharya et al. (2017) supported that when applied, RM contributes to providing warning signs; It builds on linking between historical data and foreseeing tools to develop feasible scenarios that might pose a threat to the project. In other studies, the RM process has evinced a significant correlation with PS (Moshesh et al., 2018; Muchenga, 2016; Williams, 2016). Furthermore, it was revealed that evaluating the likelihood and magnitude of risk contributed to organisational performance in the Turkish service and manufacturing industry, through inventory performance, innovation performance, and customer service (Sayilir \& Farhan, 2017). Similarly, in investigating risk management practices and their effect on construction project performance, Omer and Adeleke (2019) established that RM had a significant relationship in improving project performance in Malaysia and other nations. Irrespective of the country or industry, RM has shown evidence of its significance in enhancing project performance.

The result of the hypothesised relationship suggests that the SACI, specifically the SME sector, do recognise the importance of using RM in decision-making related to the process of managing construction risks. Project managers in the SME sector should include RM as part of their risk management activities to benefit the advantages of adopting RM practices to enhance their project performance and hence achieve PS. Therefore, executive management of organisations should rely more on statistical measurements, and reliable analysed data and motivate risk information-sharing culture in the organisation. This will lead SMEs to the continual enhancement and eventually impact project performance positively. 


\section{Contribution of the study}

By establishing the influence of RM on PS of construction SMEs, this study contributes to the applicable body of knowledge about project risk management by producing a model that will enable construction enterprises from SA and analogous developing countries to focus on a few measures of RM to curtail project risks in construction. Furthermore, this study highlights the importance of incorporating RM as part of risk management practices to attain success at the project level of SMEs within the SACI. The insights presented in this paper can be valuable information for future construction projects, practitioners, and other categories of contractors.

\section{Conclusion}

This study has established a correlation between RM and PS of SMEs in the SACI. This article illustrates results secured from a questionnaire survey from Gauteng. It was found that RM significantly influences PS of construction SMEs through delimiting the RM criteria to be adopted, establishing the level of acceptable risk and risk timeframe relevant to risk effect and risk likelihood. This result corroborates extant literature which advocates the

\section{References}

Acharya, V.V., Pedersen, L.H., Philippon, T., and Richardson, M. (2017). Measuring Systemic Risk. The Review of Financial Studies, 30 (1): 2-47. Available from: https://doi.org/10.1093/rfs/hhw088 [accessed: 01 January 2020].

Al-Ajmi, H.F., and Makinde, E. (2018). Risk Management in Construction Projects. Journal of Advanced Management Science, 6 (2): 113-116.

Albasara, H.M.M., Singh, B.K., and Pandey, V.K. (2018). The impact of Effective Risk Management on Project Success. International Journal for Technological Research in Engineering, 5 (6): 3193-3196.

Baloyi, T. and Ozumba, A. (2020). Strategic Risk Management among Small Enterprises in the Construction Industry. MATEC Web of Conferences 312, 02013 (2020). Available at: https://doi.org/10.1051/matecconf/202031202013

EPPM2018. Accessed: 01/07/2020

Canbolat, M.A., Gümrah, A. (2015). Analysis of Credit Risk Measurement Models in the Evaluation of Credit Demands. Universal Journal of Accounting and Finance, 3(1): 16-20. doi:10.13189/ujaf.2015.030103.

Chileshe, N., Hosseini, M. R, and Jepson, J. (2016). Critical Barriers to Implementing Risk Assessment and Management Practices (RAMP) in the Iranian Construction Sector. Journal of Construction in Developing Countries, 21(2): 81-112. Available from: https://dx.doi.org/10.21315/jcdc2016.21.2.5.

CIDB. Annual report (2016/2017). Available at: http://www.cidb.org.za/publications/Documents/Annual \%20Report\%202016-2017.pdf. Accessed: 12/03/2020.

Dandage, R.V., Mantha, S.S., Rane, S.B., and Bhoola, V. (2018). Analysis of interactions among barriers in project risk management. Journal of Industrial Engineering International, 14(1): 153-169. adoption of RM to achieve PS in construction. The current finding is, therefore expected to retain SMEs' upper management attention in incorporating RM as part of their risk management elements for their projects.

\section{Study limitations and future work}

The study was conducted in Gauteng; the data and survey results were collected from construction SMEs. The results are therefore limited to the context of Gauteng and cannot be generalised to the whole country, nor they can be directly applied in other countries without appropriate substantiation. Homogeneous studies in other nations could produce contradictory findings. Furthermore, the current study did not determine the influence of individual measures of RM on PS. Keeping in view that risk management warrants an emphasis on appropriate measures of RM, it is suggested that subsequent research be conducted with a perspective to expanding the knowledge of the effect of individual measure of RM on construction PS. Such a study can model the causal relationship between each measure of RM and PS criteria using, for instance, Structural Equation Modelling (SEM).

Deloach, J. (2018). Key Elements of the Risk Management Process, available from: https://www.corporatecomplianceinsights.com/keyelements-of-the-risk-management-process/. Accessed: 24/04/2020

Fernando, M.D, Leonardo, R., and Stephanía, M. (2018). Financial Risk Measurement in a Model of Supply of Raw Materials", Yoshizaki, H., Velázquez Martínez, J. and Argueta, C. (Ed.) Supply Chain Management and Logistics in Latin America, Emerald Publishing Limited: 171 181. Available from: https://doi.org/10.1108/978-178756-803-720181011 [accessed: 11/03/2020].

Field, A. (2013). Discovering statistics using IBMSPSS Statistics (4th ed.). London, England: Sage.

Firmenich, J. (2017). Customisable framework for project risk management. Construction Innovation, 17 (1):68-89. Available from: https://doi.org/10.1108/CI-042015-0022 [accessed: 01/03/2020).

Fischer, R. (2015). Barriers to effective risk management on small construction projects in South Africa. Master's thesis, Faculty of Engineering and the Built Environment, the University of the Witwatersrand, Johannesburg, South Africa.

Hair, J.F., Babin, B.J., Anderson, R.E., and Black, W.C. (2018). Multivariate Data Analysis (8th ed.). Boston: Cengage.

Hove, G. and Banjo, A. (2018). Perceptions of small business executives on determinants of performance in the construction industry in Gauteng, South Africa, Acta CommercII, 18(1), a528.https://doi.org. /10.4102/ac. v18i1.528

Hwang, B.G., Zhao, X. and Toh, L.P. (2014). Risk management in small construction projects in Singapore: status, barriers and impact. International Journal of Project Management, 32 (1):116-124.

Jaskowski, P., and Biruk, S. (2019). The Conceptual framework for construction project risk assessment. Theory and Application, 2: 27-35. 
Kotb, M.H., and Ghattas, M.M. (2018). Risk Identification Barriers in Construction Projects in MENA1. PM World Journal,7(8):1-16.

Leboea, S.T. (2017). The Factors Influencing SME Failure in South Africa. Master's thesis, School of Business, the University of Cape Town, Cape Town, South Africa.

Lu, H., Pishdad-Bozorgi, P., Wang, G., Xue, Y., and Tan, D. (2019). ICT Implementation of Small- and Medium-Sized Construction Enterprises: Organisational Characteristics, Driving Forces, and Value Perceptions. Sustainability, 11(12): 2-20.

Madani, A. El. (2018). SME Policy: Comparative Analysis of SME Definitions. International Journal of Academic Research in Business and Social Sciences, 8(8):103-114.

Mafundu, R.H., and Mafini, C. (2019). Internal constraints to business performance in black-owned small to medium enterprises in the construction industry. South African Journal of Entrepreneurship and Small Business Management, 11(1): a165. Available from: https://doi.org/10.4102/sajesbm.v11i1.165 [accessed: 25/03/2020].

Maseko, C. M. (2017). Identification of risk factors affecting construction of projects: The case of an emerging economy. Risk Governance and Control: Financial Markets and Institutions, 7(4-2): 246-259. Available from: http://doi.org/10.22495/rgc7i4c2art7

Moshesh, R., Niemann, W., and Kotzé, T. (2018). Enterprise Risk Management Implementation Challenges: A Case Study in a Petrochemical Supply Chain. South African Journal of Industrial Engineering, 29(4):230-244.

Muchenga, I. (2016). Political Risk Management on International Construction Projects. Master's thesis, Project Management, the University of Cape Town, Cape Town, South Africa.

Muzondo, F.T., and McCutcheon, R.T. (2018). The relationship between project performance of emerging contractors in government infrastructure projects and their experience and technical qualifications. Journal of the South African Institution of Civil Engineering, 60(4): 2533.

Mwangi, H.M., and Ngugi, L. (2018). Risk management practices and performance of construction projects in Nairobi city county Government Kenya. International Academic Journal of Information Sciences and Project Management, 3 (2):111-136.

Naji, H.I., and Ali, R.H. (2017). Risk Response Selection in Construction Projects. Civil Engineering Journal, 3(12): 1208-1221. doi: 10.28991/cej-030950.

Naude, M.J., and Chiweshe, N. (2017). A proposed operational risk management framework for small and medium enterprises. South African Journal of Economic and Management Sciences, 20(1), a1621. Available from: https://doi.org/10.4102/sajems.v20i1.1621 [accessed: 12/04/2020].

Nawaz, A., Shah, S.A.R, Sajid, M., and Khalid, M.I. (2019). An Innovative Framework for Risk Management in Construction Projects in Developing Countries: Evidence from Pakistan. Molecular Diversity Preservation International Journals, 7(24): 2-10.
Oduoza, C.F., Odimabo, O., and Tamparapoulos, A. (2017). Framework for Risk Management Software System for SMEs in the Engineering Construction Sector. Procedia Manufacturing, 11:1231-1238

Okereke, O.C. (2017). Causes of failure and abandonment of projects and project deliverables in Africa. PM World Journal, 6(1):1-16.

Omer, MS., and Adeleke, A.Q. (2019). Systematic Critical Review of Risk Management in Malaysian Construction Companies. Journal of Humanities and Social Sciences Studies (JHSSS), 1(5):60-70

Osuizugbo, I.C. (2019). Failure Factors Affecting Building Project Success in Nigeria: Design and Construction Phase. IOSR Journal of Mechanical and Civil Engineering (IOSRJMCE), 16 (1): 01-11.

Pallant, J. (2016). SPSS Survival Manual: A step by step guide to data analysis using IBM SPSS (6th ed.). London, UK: McGraw-Hill Education.

Potensis. (2017). Global Construction. Available from: https://www.potensis.com/insights/global-construction/ [accessed: 08/04/2020]

Rambo, C.M., and Oketch, T. (2018). Influence of Risk Assessment on Performance of SME Projects in Machakos County, Kenya. European Scientific Journal, 14 (19):181-205. Available from: http://dx.doi.org/10.19044/esj.2018.v14n19p181 [accessed:11/04/ 2020].

Rehacek, P. (2017a). Risk management in construction projects. Journal of Engineering and Applied sciences, 12(20): 5347-5352.

Rungani, E.C., and Potgieter, M. (2018). The impact of financial support on the success of small, medium and micro-enterprises in the Eastern Cape province. Acta CommercII 18(1): a591. Available from: https://doi.org/10.4102/ ac. v18i1.591.

Rwelamila, E.K. (2018). Understanding the risk in South African construction projects-a case of the Western Cape. Master's thesis (Project Management). The University of Cape Town, Cape Town, South Africa.

Sayilir, Ö., and Farhan, M. (2017). Enterprise Risk Management and Its Effect on Firm Value in Turkey. Journal of Management Research, 9(1):86-99

Segal, T. (2019). Common Methods of Measurement for Investment Risk Management. Available from: https://www.investopedia.com/ask/answers/041415/what -are-some-common-measures-risk-used-riskmanagement.asp [accessed: 16//04/ 2020].

Sifumba, C.M., Mothibi, K.B., Anthony Ezeonwuka, A., Qeke, S., and Matsoso, M.L. (2017). The risk management practices in the manufacturing SMEs in Cape Town. Problems and Perspectives in Management, 15 (2): 386-403.

Simota, J., Tupa, J., and Steiner, F. (2017). Risk Management to Enhance Performance in the construction industry SME Sector. Theory and Case Study, IntechOpen. doi:10.5772/intechopen.68798.

StatsSA. (2018). Quarterly Employment Statistics; September 2018, Publication P0277. Statistics South Africa, www.statssa.gvo.za

Szymański, P. (2017). Risk management in construction projects. Procedia Engineering, 208: 174182 
Tabachnick, B.G., and Fidell, L.S. (2019). Using Multivariate Statistics (7ed.). Pearson, United States of America.

Teuma, J. (2019). The attitudes and approaches to risk management among Gozitan SMEs within the construction and financial services sectors. Bachelor's dissertation (Insurance and risk management). University of Malta, Malta.

van Winsen, F., de Mey, Y., Lauwers, L., Van Passel, S., Vancauteren, M., and Wauters, E. (2016).
Determinants of risk behaviour: effects of perceived risks and risk attitude on farmer's adoption of risk management strategies. Journal of Risk Research, 19(1):56-78

Williams, P. (2016). Managing Measurement of risk in Building and Civil Engineering (1st ed.). Chichester, West Sussex: United Kingdom, Wiley Blackwell.

Zoghi, F.S. (2017). Risk Management Practices and SMEs: An empirical study on Turkish SMEs. International Journal of Trade, Economics and Finance, 8 (2): 123-127. 